\title{
Differential Responses of Bladder Lumbosacral and Thoracolumbar Dorsal Root Ganglion Neurons to Purinergic Agonists, Protons, and Capsaicin
}

\author{
Khoa Dang, ${ }^{1}$ Klaus Bielefeldt, ${ }^{2}$ and G. F. Gebhart ${ }^{1}$ \\ ${ }^{1}$ Department of Pharmacology, The University of Iowa, Iowa City, Iowa 52242, and 2Department of Internal Medicine, University of Pittsburgh, Pittsburgh, \\ Pennsylvania 16213
}

\begin{abstract}
The present study explored differences in sensitivity to purinergic agonists, protons, and capsaicin in lumbosacral (LS) and thoracolumbar (TL) sensory neurons that innervate the rat urinary bladder. The majority of LS neurons (93\%) were sensitive to $\alpha$, $\beta$-methyleneATP $(\alpha, \beta$-metATP) compared with $50 \%$ of TL neurons. Based on inactivation kinetics, a slowly desensitizing current evoked by $\alpha, \beta$-metATP predominated in LS neurons (86\%) compared with mixed components that characterized TL neuron responses (58\%). The density of the slowly desensitizing current was greater in LS than in TL neurons (LS, $34.4 \pm 5.3 \mathrm{pA} / \mathrm{pF}$; TL, $2.5 \pm 0.8 \mathrm{pA} / \mathrm{pF}$ ). Almost all neurons in both ganglia responded to protons and to capsaicin (LS, 100\%; TL, 98\%). Proton-activated currents in bladder sensory neurons exhibited distinct inactivation kinetics as fast, intermediate, slowly desensitizing, and sustained components. More than one component was expressed in every cell. Although there was no difference in the percentage of neurons expressing more than one component, the density of the sustained current was significantly greater in LS than in TL neurons (LS, $86.1 \pm 16 \mathrm{pA} / \mathrm{pF}$; TL, $30.3 \pm 7 \mathrm{pA} / \mathrm{pF}$ ). Similarly, the capsaicin-evoked current was greater in LS than in TL neurons (LS, $129.6 \pm 17 \mathrm{pA} / \mathrm{pF}$; TL, $86.9 \pm 11 \mathrm{pA} / \mathrm{pF})$. Finally, a greater percentage of TL neurons bound isolectin B4 than LS neurons (LS, 61\%; TL, 85\%). The greater degree of $\alpha$, $\beta$-metATP, proton, and capsaicin responsiveness, in addition to differences in current type and current densities, in LS and TL neurons suggests that bladder pelvic and hypogastric/lumbar splanchnic afferents are functionally distinct and likely mediate different sensations arising from the urinary bladder.
\end{abstract}

Key words: bladder; dorsal root ganglia; $\alpha, \beta$-metATP; ATP; P2X receptors; protons; capsaicin; IB4; A317491

\section{Introduction}

As a temporary storage organ, the urinary bladder is exposed to varying volumes of urine of differing composition, which ultimately triggers micturition and also sensation. Importantly, interactions between the bladder urothelium and terminals of sensory neurons, which can be activated by mechanical and/or chemical stimuli, play a significant role in both the regulation of micturition and sensations arising from the bladder (Andersson, 2002). For example, distension of the bladder releases ATP from urothelial cells, which activates sensory neurons, potentially triggering reflex micturition (Vlaskovska et al., 2001). Deletion of $\mathrm{P}_{2} \mathrm{X}_{3}$ receptors in mice results in bladder hyporeflexia, increased voiding volume, and decreased micturition frequency (Cockayne et al., 2000). Similarly, activation of the capsaicin receptor TRPV1 contributes to the micturition reflex, as shown by bladder hyporeflexia in TRPV1 knock-out mice and an association be-

Received Dec. 22, 2004; revised March 9, 2005; accepted March 9, 2005.

This work was supported by National Institutes of Health Grants NS 35790 and NS 19912. We thank Michael Jarvis (Abbott Laboratories, Abbott Park, L) for the gift of A317491, Michael Burcham for preparation of the graphics, and Sherry Kardos for immunochistochemistry.

Correspondence should be addressed to Dr. Khoa Dang, Department of Pharmacology, University of lowa, lowa City, IA 52242. E-mail: khoa-dang@uiowa.edu.

D01:10.1523/JNEUROSCI.5239-04.2005

Copyright $\odot 2005$ Society for Neuroscience $\quad$ 0270-6474/05/253973-12\$15.00/0 tween detrussor hyperactivity and increased TRPV1 expression (Birder et al., 2002; Brady et al., 2004).

The bladder is innervated by the pelvic and hypogastric/lumbar splanchnic nerves with cell bodies located in thoracolumbar (TL) and lumbosacral (LS) dorsal root ganglia (DRGs), respectively (Applebaum et al., 1980). Most studies have focused on the pelvic nerve, transection of which abolishes bladder contractions to repetitive filling, suggesting that the pelvic nerve is important for the sensation of bladder distension and micturition (Kontani and Hayashi, 1997; Meen et al., 2001). However, the hypogastric/ lumbar splanchnic nerve is also activated by mechanical and chemical stimulation of the bladder, contributes to the regulation of micturition, and may play an enhanced role in cystitis (Moss et al., 1997; Mitsui et al., 2001).

Accumulating evidence suggests that different nerves innervating the same organ are distinct functionally. For example, the colon is also innervated by the pelvic and hypogastric/lumbar splanchnic nerves, and the mechanosensitivity and location of receptive endings in the colon differ between the two nerves (Brierley et al., 2004), as do the passive and active electrical properties of colonic TL and LS neurons (Gold and Traub, 2004). In addition, hypogastric/splanchnic sensory afferents reportedly respond more robustly to chemical stimuli than do pelvic counterparts (Moss et al., 1997). Finally, the innervations of the bladder 
body and proximal urethra tract exhibit distinct histological and electrical properties in addition to differential expression of TRPV1 and voltage-gated $\mathrm{Na}^{+}$and $\mathrm{Ca}^{2+}$ currents (Yoshimura et al., 2003). Despite such evidence suggesting that bladder sensory afferent pathways are distinct functionally, there has been no systematic study of how bladder LS and TL neurons differ, which could further support/advance our knowledge of micturition and sensory function of the bladder in normal and pathological states. Considering the importance of P2X, TRPV1, and, potentially, acid-sensing ion channels (ASICs) in micturition and bladder sensory function, we hypothesized that the properties of urinary bladder sensory neurons differ in TL and LS DRGs and examined in the present study purinergic, proton, and capsaicin sensitivity of retrogradely labeled bladder neurons. A preliminary report of these results has been published previously in abstract form (Dang et al., 2004).

\section{Materials and Methods}

Male Sprague Dawley rats (200-300 g; Harlan, Indianapolis, IN) were used for the experiments. Rats were housed under a $12 \mathrm{~h}$ light/dark cycle with ad libitum access to food and water. Animal handling adhered to the National Research Council Guide for the Care and Use of Laboratory Animals; the experimental protocol was approved by the Animal Care and Use Committee of The University of Iowa.

\section{Cell labeling}

Under pentobarbital anesthesia $(50 \mathrm{mg} / \mathrm{kg}$, i.p.), the rat bladder was exposed surgically (lower abdominal incision, $\sim 1 \mathrm{~cm}$ in length), and 1,1'dioctadecyl-3,3,3',3-tetramethylindocarbocyanine methanesulfonate (DiI; $100 \mathrm{mg}$ in $2 \mathrm{ml}$ of DMSO; Molecular Probes, Eugene, OR) was injected into six to eight sites within the wall of the bladder base around the trigone using a 30 gauge needle ( $6 \mu$ l per site). Any visible leakage of DiI during injection was wiped off with a cotton swab. The incision was closed with a 4.0 silk suture, and rats were allowed to recover until the DRGs were harvested 14-21 d later for electrophysiological recordings. We checked every rat postmortem for leakage of DiI by examining the bladder and surrounding tissues after the TL or LS DRGs were removed. No labeling in any tissue other than the bladder was noted.

\section{Cell dissociation and culture}

Rats were anesthetized as above and decapitated, and the T13-L2 or L6-S2 DRGs were removed rapidly. The ganglia were minced and incubated at $37^{\circ} \mathrm{C}$ in $5 \% \mathrm{CO}_{2}$ for $60 \mathrm{~min}$ in serum-free, supplemented Neuro-A medium (5\% B27 supplements, $0.5 \mathrm{~mm} \mathrm{L-glutamine,} \mathrm{and} \mathrm{1 \%}$ penicillin/streptomycin mixture; all from Invitrogen, Grand Island, NY) containing collagenase (type $4 ; 2 \mathrm{mg} / \mathrm{ml})$ and trypsin $(1 \mathrm{mg} / \mathrm{ml}$; Worthington Biochemical, Lakewood, NJ). Tissue fragments were triturated gently to encourage cell dissociation. Cells were collected by a $5 \mathrm{~min}$ centrifugation at $150 \times g$, washed three times with supplemented Neuro-A medium (without enzymes), and resuspended in supplemented, enzyme-free Neuro-A medium. The cells were plated on polyD-lysine-coated coverslips (Becton Dickinson Labware, Bedford, MA) and incubated at $37^{\circ} \mathrm{C}$ in $5 \% \mathrm{CO}_{2}$ for $2-3 \mathrm{~h}$ before electrophysiological studies. Acutely dissociated neurons were round and devoid of any processes, thus reducing potential space-clamp errors. Only bladder sensory neurons (i.e., DiI-containing DRG neurons) were studied. All recordings were performed within $10 \mathrm{~h}$ after plating.

\section{Solutions and electrophysiological recordings}

Coverslips with cells were transferred to a recording chamber $(1 \mathrm{ml})$ superfused continuously $(2 \mathrm{ml} / \mathrm{min})$ with external solution containing the following (in mM): $140 \mathrm{NaCl}, 5 \mathrm{KCl}, 2 \mathrm{MgCl}_{2}, 2 \mathrm{CaCl}_{2}, 10 \mathrm{HEPES}$, and 10 glucose. The $\mathrm{pH}$ was adjusted to 7.4 with $\mathrm{NaOH}(310 \mathrm{mOsm})$. Neurons that innervated the bladder were identified by DiI content using a rhodamine filter (excitation wavelength, $\sim 546 \mathrm{~nm}$; barrier filter, 580 $\mathrm{nm})$. Fire-polished micropipettes with tip resistances of 1.5-2 $\mathrm{M} \Omega$ were used for current- and voltage-clamp recordings. The uncompensated series resistance was generally approximately $\leq 7 \mathrm{M} \Omega$. The pipette was filled with an internal solution consisting of the following (in $\mathrm{mM}$ ): 130 $\mathrm{KCl}, 1 \mathrm{CaCl}_{2}, 1 \mathrm{MgCl}_{2}, 10$ EGTA, 10 HEPES, $4 \mathrm{Na}_{2} \mathrm{ATP}$, 0.5 Tris-GTP, and $0.5 \mathrm{GDP}$. The $\mathrm{pH}$ was adjusted to $7.2 \mathrm{using} \mathrm{KOH}(310 \mathrm{mOsm})$. After establishing the whole-cell configuration, the voltage was clamped at $-70 \mathrm{mV}$ using an Axopatch 200B amplifier (Axon Instruments, Union City, CA), digitized at $1 \mathrm{kHz}$ (Digidata 1350; Axon Instruments), and controlled by Clampex software (pClamp 9; Axon Instruments). Cell capacitance was obtained by reading the value from the Axopatch 200B amplifier. Recordings began $2-3$ min after establishing the whole-cell configuration to ensure stable recording conditions.

Drugs were applied using a fast-step SF-77B superfusion system (Warner Instruments, Hamden, CT) with a three-barrel pipette placed in close proximity $(100 \mu \mathrm{m})$ to the cell. Complete solution exchange could be obtained within $24.3 \pm 1 \mathrm{~ms}$ by measuring the time constant from switching from the standard external solution to one containing $40 \mathrm{~mm}$ $\mathrm{KCl}$. Agonists were applied for $4 \mathrm{~s}$, whereas antagonists were superfused for $30 \mathrm{~s}$ before the application of agonists. A washout period of $4 \mathrm{~min}$ was allowed between agonist applications. Drugs were obtained from SigmaAldrich (St. Louis, MO) and prepared fresh from stock solutions on the day of the experiment. All experiments were performed at room temperature $\left(21-23^{\circ} \mathrm{C}\right)$.

\section{Immunohistochemistry}

Isolectin B4 labeling. After the recording protocol was completed, isolectin B4 (IB4) conjugated to AlexaFluor 488 (Molecular Probes, Eugene, OR) was applied to the recording chamber for $10 \mathrm{~min}$ at a final concentration of $10 \mu \mathrm{g} / \mathrm{ml}$ (from a stock concentration of $1 \mathrm{mg} / \mathrm{ml}$ ). The recording chamber was then washed for $3 \mathrm{~min}$ to remove any excess conjugated IB4. IB4-positive neurons displayed a bright green ring around the cell surface when barrier filtered at $510 \mathrm{~nm}$. To confirm the specificity of IB4 labeling, DRG cells were preincubated with excess unconjugated IB4 $(0.2 \mathrm{mg} / \mathrm{ml}$; Sigma-Aldrich) before applying conjugated IB4. No labeling was observed (data not shown). In addition, we also compared IB4 labeling using FITC-IB4 (Sigma-Aldrich) and AlexaFluor 488-IB4 at the same concentration $(2 \mu \mathrm{g} / \mathrm{ml})$ in serially cut DRG slices. AlexaFluor 488-IB4 always labeled more neurons than FITC-IB4 (data not shown); however, we did not quantify the percentages of IB4-positive neurons labeled with FITC or AlexaFluor 488 in DRG sections.

$P 2 X$ and TRVP1 labeling. To examine colocalization of receptors, we performed triple labeling of $\mathrm{P} 2 \mathrm{X}_{3}$ and $\mathrm{P} 2 \mathrm{X}_{2}$ or $\mathrm{P} 2 \mathrm{X}_{2}$ and TRPV1. Fluorogold (4\%; Biotium, Hayward, CA) was injected into the bladder base in three rats as described for DiI above. Rats were killed 14 d later, and DRGs were rapidly removed, fixed in $4 \%$ paraformaldehyde (Sigma-Aldrich) for $4 \mathrm{~h}$, and cryoprotected in 30\% sucrose for $3 \mathrm{~d}$ before cutting. DRGs were sectioned at $10 \mu \mathrm{m}$ with a Leica (Nussloch, Germany) 3M 3050 cryostat. DRG sections were blocked with $3 \%$ goat serum in $0.01 \mathrm{~m}$ PBS (Sigma-Aldrich) for $2 \mathrm{~h}$ before incubation of primary antibodies for $24 \mathrm{~h}$ at $4^{\circ} \mathrm{C}$. Primary antibodies (rabbit anti-rat) were applied at the following dilutions: $\mathrm{P}_{3}$, 1:100; $\mathrm{P}_{2}$, 1: 200; TRPV1, 1:50 (EMD Biosciences, La Jolla, CA). Primary antibodies were aspirated, and sections were washed three times for 15 min with 0.01 M PBS. Secondary antibodies (antirabbit) conjugated to either AlexaFluor 488 or 568 (Molecular Probes) were applied for $4 \mathrm{~h}$ and washed three times for $15 \mathrm{~min}$ with $0.01 \mathrm{M}$ PBS. Sections were mounted with fluorescence mount (Sigma-Aldrich) and viewed with a Nikon microscope equipped with separate fluorescence filters. Images were captured with a model 2.3.1 SPOT digital camera (Diagnostic Instruments, Sterling Heights, MI). For control experiments, primary antibodies were omitted and/or blocked with corresponding antigenic peptides for $24 \mathrm{~h}$. No labeling was observed (data not shown).

\section{Data analyses}

All data are given as mean \pm SEM. Analyses were performed using the software package Graph Pad Prism 4 (Graph Pad Software, San Diego, CA). Sigmoidal dose-response curves were generated using the following equation: $Y=A /\left[1+\exp \left[-\left(\operatorname{LogEC}_{50}-X\right) / B\right)\right]$, where $X$ is the logarithm of concentration and $Y$ is the response and starts at 0 and goes to $A$ with a sigmoidal shape. $B$ is the Hill slope. Desensitization kinetics were fitted with a standard exponential equation: $Y=K_{0}+K_{1} \times \exp (-t / \tau)$, 
where $Y$ is the current amplitude at time $t, K_{0}$ is the amplitude of the sustained component, and $\tau$ is the time constant. $K_{0}$ and $K_{1}$ represent the contribution to current amplitude from the fast and slow components of the current, respectively.

To compare percentage differences, a $\chi^{2}$ test was used. All other comparisons were made using Student's unpaired $t$ test. Results were considered to be statistical significant when $p<0.05$.

\section{Results}

Bladder innervation density and cell size characteristics

A total of six rats were used to estimate the number of primary afferent neurons that innervate the bladder. We randomly chose six coverslips (one from each rat) containing T13-L2 or L6-S2 DRG cells and counted the total number of DiI-labeled neurons. In the L6-S2 DRGs, 219 of 4015 neurons were DiI labeled, constituting $5.4 \pm 0.5 \%$ of the sample. In contrast, only $2.0 \pm 0.3 \%$ (106 of 5316) of T13-L2 DRG neurons were DiI positive $(p<$ $0.05)$, suggesting that the number of bladder DRG neurons is $\sim 2.5$-fold greater in LS than in TL DRGs.

Next, we examined whether whole-cell capacitance (as an index of cell size) differed between LS and TL bladder neurons. As illustrated in Figure $1 A$, the distribution of cell capacitances in LS and TL bladder neurons differed significantly. A significant proportion of LS bladder neurons ( 49 of $194 ; 25.3 \%$ ) had a wholecell capacitance $<20 \mathrm{pF}$, suggesting that these neurons were small (Fig. 1B). Most remaining neurons (144 of 194; 74\%) had capacitances between 20 and $60 \mathrm{pF}$, consistent with medium size. In contrast, no TL bladder neurons had a whole-cell capacitance $<20 \mathrm{pF}$ ( $p<0.001$ vs LS bladder neurons), whereas 19 of 123 (15.4\%) were considered to be large because cell capacitance was $>60 \mathrm{pF}(p<$ 0.01 ); most (104 of 123; 85.4\%) TL bladder neurons were mediumsized cells (Fig. $1 B$ ). Consistent with the difference in size distribution, the mean capacitance of LS bladder neurons $(27.7 \pm 0.7 \mathrm{pF})$ differed significantly from the mean capacitance of TL bladder neurons $(45.3 \pm 1.3 \mathrm{pF} ; p<0.001)$.

\section{Characterization of bladder sensory neuron responses to ATP LS bladder neurons}

To evaluate functionally the presence of purinergic receptors on bladder neurons, we applied the nonselective agonist ATP. ATP superfusion triggered rapidly activating inward currents in 53 of $54(98.1 \%)$ LS neurons (Fig. 2A-C), consistent with the presence of $\mathrm{P} 2 \mathrm{X}$ receptors. Based on the kinetics of current decay, we differentiated fast, slow, and mixed desensitizing currents, with a predominance of the slowly desensitizing current found in 46 of $53(86.8 \%)$ neurons (Fig. 2 B). Three (5.7\%) and four (7.5\%) LS neurons expressed fast (Fig. 2A) and mixed (Fig. 2C) current kinetics, respectively. The fast desensitizing current peaked within $237.5 \pm 67 \mathrm{~ms}$ and desensitized with a time constant of $241.2 \pm 42 \mathrm{~ms}$. The slowly desensitizing current reached the maximal amplitude within $1.03 \pm 0.07 \mathrm{~s}$ and decayed with a time constant of $4.44 \pm 0.42 \mathrm{~s}$. The sample trace shown in Figure $2 \mathrm{C}$ suggests that the slowly desensitizing component contributed significantly to the response in cells with mixed current kinetics. Consistent with this visual impression, a double-exponential fit revealed that the slow component amounted to $83 \pm 6 \%$ of the peak current. The mean current density for fast, mixed, and slowly desensitizing components was $5.3 \pm 0.6,9.9 \pm 2.5$, and $75.3 \pm 14 \mathrm{pA} / \mathrm{pF}$, respectively.

\section{TL bladder neurons}

In contrast to LS neurons, application of ATP evoked currents in only 34 of $52\left(65.4 \% ; \chi^{2}=17.2 ; p<0.01\right)$ TL neurons. Thirteen of $34(38.2 \%), 4$ of $34(11.8 \%)$, and 17 of 34 (50\%) TL neurons
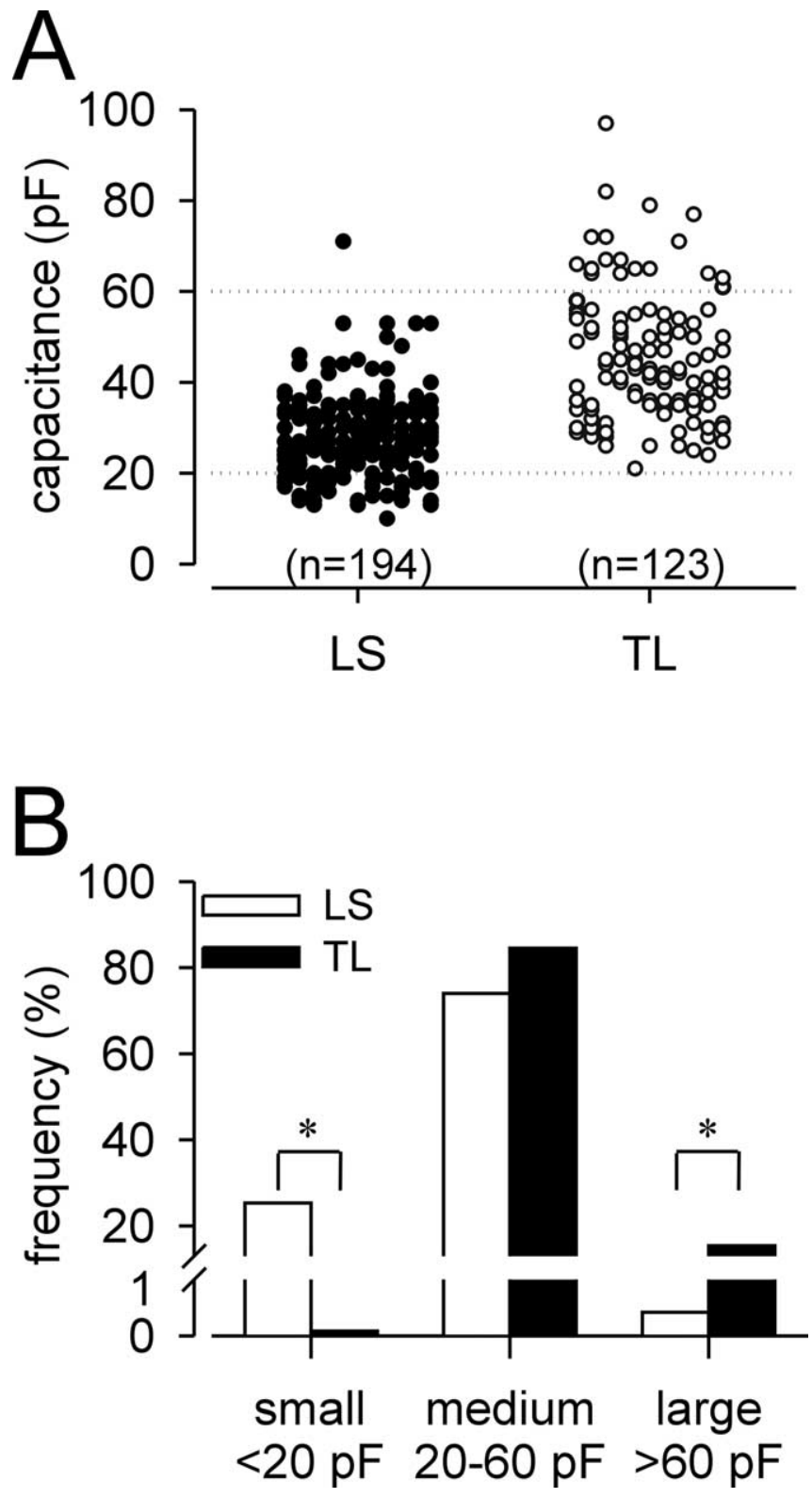

Figure 1. Whole-cell capacitance (an index of cell size) in bladder sensory neurons. $\boldsymbol{A}$, Scatter plot of whole-cell capacitance showing different patterns of cell size distribution in LS and TL DRGs. $\boldsymbol{B}$, Frequency distribution of whole-cell capacitance in bladder sensory neurons. No cells had a capacitance $<20 \mathrm{pF}$ in TL DRGs, whereas a significantly lower number of LS neurons (open bar) had a capacitance $>60 \mathrm{pF}$ compared with TL counterparts (filled bar). ${ }^{*} p<0.05$.

expressed slowly, fast, and mixed desensitizing currents, respectively (Fig. 2D-F). The slowly desensitizing component peaked within $1445 \pm 168 \mathrm{~ms}$ and decayed with a time constant of $3.75 \pm$ $0.9 \mathrm{~s}$. The fast component peaked within $295.7 \pm 26 \mathrm{~ms}$ and had a desensitization constant of $309.8 \pm 24 \mathrm{~ms}$. The mixed current peaked just as rapidly as the fast desensitizing component, with a time-to-peak of $292.5 \pm 21 \mathrm{~ms}$. Based on exponential fitting, the slowly desensitizing current contributed an estimated $42 \pm 7 \%$ of the peak current. The mean current density for fast, mixed, and slowly desensitizing currents was $4.3 \pm 0.4,7.3 \pm 1.5$, and $4.6 \pm$ $0.7 \mathrm{pA} / \mathrm{pF}$, respectively. Although the current density of fast and mixed currents did not differ between LS and TL neurons, LS neurons with slowly desensitizing kinetics expressed significantly greater peak current densities $(p<0.001)$. Similarly, in LS neurons with mixed kinetics, the slow component contributed a greater 
percentage of the peak current compared with TL counterparts $(p<0.001)$. Differences between LS and TL neurons are summarized in Table 1.

\section{Characterization of $\mathrm{P} 2 \mathrm{X}$} receptor-mediated currents in bladder sensory neurons

\section{LS bladder neurons}

Because ATP is a nonselective purinergic agonist, we examined the effects of $\alpha, \beta$ methyleneATP $(\alpha, \beta$-metATP $)$, a selective homomeric $\mathrm{P}_{2} \mathrm{X}_{1}$, homomeric $\mathrm{P} 2 \mathrm{X}_{3}$, and heteromeric $\mathrm{P}_{2} \mathrm{X}_{2 / 3}$ receptor agonist (Dunn et al., 2001). Application of $\alpha, \beta$ metATP evoked an inward current in 50 of 54 (93\%) LS bladder neurons (Fig. 2A-C). In three neurons, only ATP and not $\alpha, \beta$ metATP triggered inward currents. Based on the current kinetics described above, we identified a slow current in 43 of 50 $(86 \%)$ (Fig. $2 B$ ), a fast current in 3 of 50 $(6 \%)$, and a mixed current in the remaining 4 of 50 (8\%) LS neurons. The activating and desensitization kinetics were similar to those obtained in response to ATP and are summarized in Table 2 . In neurons with mixed kinetics, the slowly desensitizing component did not decay sufficiently for analysis, and we therefore could not estimate the contribution of the slowly desensitizing current to the total current. The mean fast, mixed, and slowly desensitizing currents in LS neurons were $2.5 \pm 0.8,4.2 \pm 1.0$, and $34.4 \pm 5.3 \mathrm{pA} / \mathrm{pF}$, respectively, with neurons expressing the slowly desensitizing component having the greatest peak current density $(p<0.001)$. Compared with the nonspecific agonist ATP, peak current densities were significantly less with $\alpha, \beta$-metATP $(p<0.05)$.

\section{TL bladder neurons}

As was seen for LS bladder neuron responses to ATP and $\alpha, \beta$ metATP, $\alpha, \beta$-metATP did not trigger inward currents in all TL bladder neurons that responded to ATP. Only 26 of 52 (50\%) TL neurons responded to $\alpha, \beta$-metATP (comparison between LS and TL neurons, $\left.\chi^{2}=21.6 ; p<0.01\right)$. In eight TL neurons, ATP but not the more selective $\mathrm{P} 2 \mathrm{X}$ agonist $\alpha, \beta$-metATP triggered inward currents that slowly activated and desensitized. Similar to the effects of ATP, $\alpha, \beta$-metATP triggered slow currents in 5 of 26 (19.2\%), fast currents in 6 of $26(23.1 \%)$, and mixed currents in 15 of $26(57.7 \%)$ TL neurons. Current kinetics are summarized in Table 2. Based on exponential fitting, the slowly desensitizing component contributed $29.4 \pm 5 \%$ of the peak current in cells with mixed kinetics. When normalized to cell size, the mean current density for fast, mixed, and slowly desensitizing currents was $1.8 \pm 0.3,2.6 \pm 0.3$, and $2.5 \pm 0.8 \mathrm{pA} / \mathrm{pF}$, respectively. Although there was no difference between densities of $\alpha, \beta$-metATPevoked currents in TL neurons, the slowly desensitizing current density was significantly less in TL than in LS neurons $(p<$ $0.001)$. In addition, peak current densities were significantly less after activation with $\alpha, \beta$-metATP when compared with the nonspecific agonist ATP $(p<0.05)$.
LS
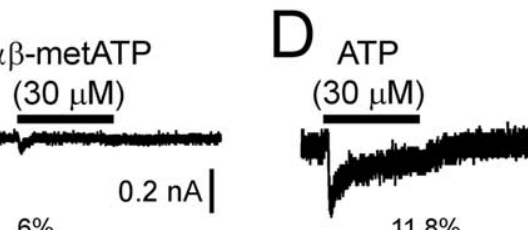

E

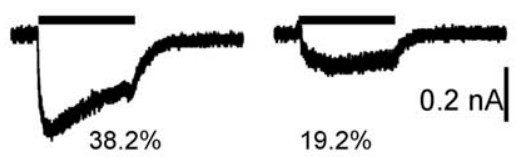

$86 \%$

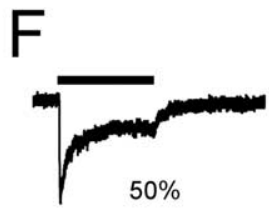

$0.2 \mathrm{nA}$ $\alpha \beta$-metATP $(30 \mu \mathrm{M})$

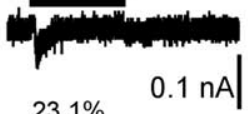

TL

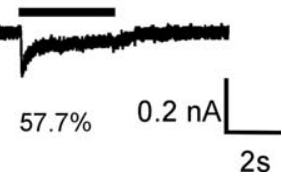

Figure 2. Purinergic agonist-activated currents in bladder sensory neurons. Fifty-three of 54 and 50 of 54 LS neurons responded to ATP and $\alpha, \beta$-metATP, respectively. Based on inactivation kinetics, three distinct current types were identified in

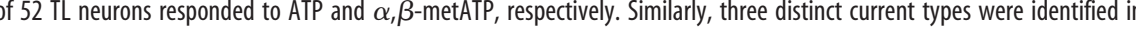
panels in $\boldsymbol{D}-\boldsymbol{F}, \alpha, \beta$-metATP evoked smaller fast, slowly, and mixed desensitizing currents.

Table 1. Summary of frequency of responses to and current densities evoked by ATP, $\boldsymbol{\alpha}, \boldsymbol{\beta}$-metATP, protons, and capsaicin in bladder sensory neurons

\begin{tabular}{lcc}
\hline & LS neurons & TL neurons \\
\hline ATP & & \\
$\quad$ Percentage responding & $98 \%(53 / 54)$ & $65 \%(34 / 52)^{*}$ \\
I density (pA/pF) & & \\
$\quad$ Fast & $5.3 \pm 0.6$ & $4.3 \pm 0.4$ \\
$\quad$ Slow & $75.3 \pm 14$ & $4.6 \pm 0.7^{*}$ \\
$\quad$ Mixed & $9.9 \pm 2.5$ & $7.3 \pm 1.5$ \\
$\alpha \beta$-metATP & & \\
$\quad$ Percentage responding & $93 \%(50 / 54)$ & $50 \%(26 / 52)^{*}$ \\
I density (pA/pF) & & \\
$\quad$ Fast & $2.5 \pm 0.8$ & $1.8 \pm 0.3$ \\
$\quad$ Slow & $34.4 \pm 5.3$ & $2.5 \pm 0.8^{*}$ \\
$\quad$ Mixed & $4.2 \pm 1$ & $2.6 \pm 0.3$ \\
Protons & & \\
$\quad$ Percentage responding & $78 \%(42 / 54)$ & $87 \%(45 / 52)$ \\
I density (pA/pF) & & \\
$\quad$ Fast & & $48.2 \pm 10$ \\
$\quad$ Intermediate & $56.4 \pm 10$ & $59 \pm 12$ \\
$\quad$ Slow & $57.8 \pm 11$ & $74.8 \pm 15$ \\
$\quad$ Sustained & $52.2 \pm 16$ & $30.3 \pm 7^{*}$ \\
Capsaicin & $86.1 \pm 16$ & $87 \pm 11^{*}$ \\
$\quad$ Percentage responding & & \\
I density (pA/pF) & $91 \%(49 / 54)$ & $92 \%(48 / 52)$ \\
\hline
\end{tabular}

Data are a comparison between $\mathrm{LS}$ and $\mathrm{TL}$ neurons $\left({ }^{*} p<0.05\right)$.

$P 2 X$ receptor dose-response relationship

We next determined the dose-response relationship for the two purinergic agonists by applying either $\alpha, \beta$-metATP or ATP in increasing concentrations. To control for differences in current densities, we expressed current as a fraction of relative current at 
Table 2. Summary of purinergic agonist-evoked current kinetics in bladder sensory neurons

\begin{tabular}{|c|c|c|c|c|c|c|}
\hline & \multicolumn{3}{|l|}{ ATP } & \multicolumn{3}{|l|}{$\alpha \beta$-metATP } \\
\hline & $\operatorname{ttp}(\mathrm{ms})$ & tau 1 (ms) & tau 2 (ms) & $\operatorname{ttp}(\mathrm{ms})$ & tau 1 (ms) & tau 2 (ms) \\
\hline \multicolumn{7}{|l|}{ LS } \\
\hline Fast & $238 \pm 67$ & $241 \pm 42$ & $\mathrm{n} / \mathrm{a}$ & $272 \pm 51$ & $226 \pm 54$ & $\mathrm{n} / \mathrm{a}$ \\
\hline Slow & $1030 \pm 70$ & $4440 \pm 420$ & $\mathrm{n} / \mathrm{a}$ & $2329 \pm 130$ & $3728 \pm 533$ & $\mathrm{n} / \mathrm{a}$ \\
\hline Mixed & $255 \pm 50$ & $241 \pm 18$ & $3219 \pm 925$ & $253 \pm 32$ & $232 \pm 41$ & $\mathrm{n} / \mathrm{a}$ \\
\hline \multicolumn{7}{|l|}{ TL } \\
\hline Fast & $296 \pm 26$ & $310 \pm 24$ & $n / a$ & $320 \pm 23$ & $285 \pm 31$ & $\mathrm{n} / \mathrm{a}$ \\
\hline Slow & $1445 \pm 168$ & $3750 \pm 900$ & $n / a$ & $2580 \pm 436$ & $4305 \pm 1022$ & $\mathrm{n} / \mathrm{a}$ \\
\hline Mixed & $293 \pm 21$ & $239 \pm 26$ & $2931 \pm 251$ & $316 \pm 31$ & $317 \pm 37$ & $3827 \pm 866$ \\
\hline
\end{tabular}

ttp, Time to peak; n/a, not applicable.
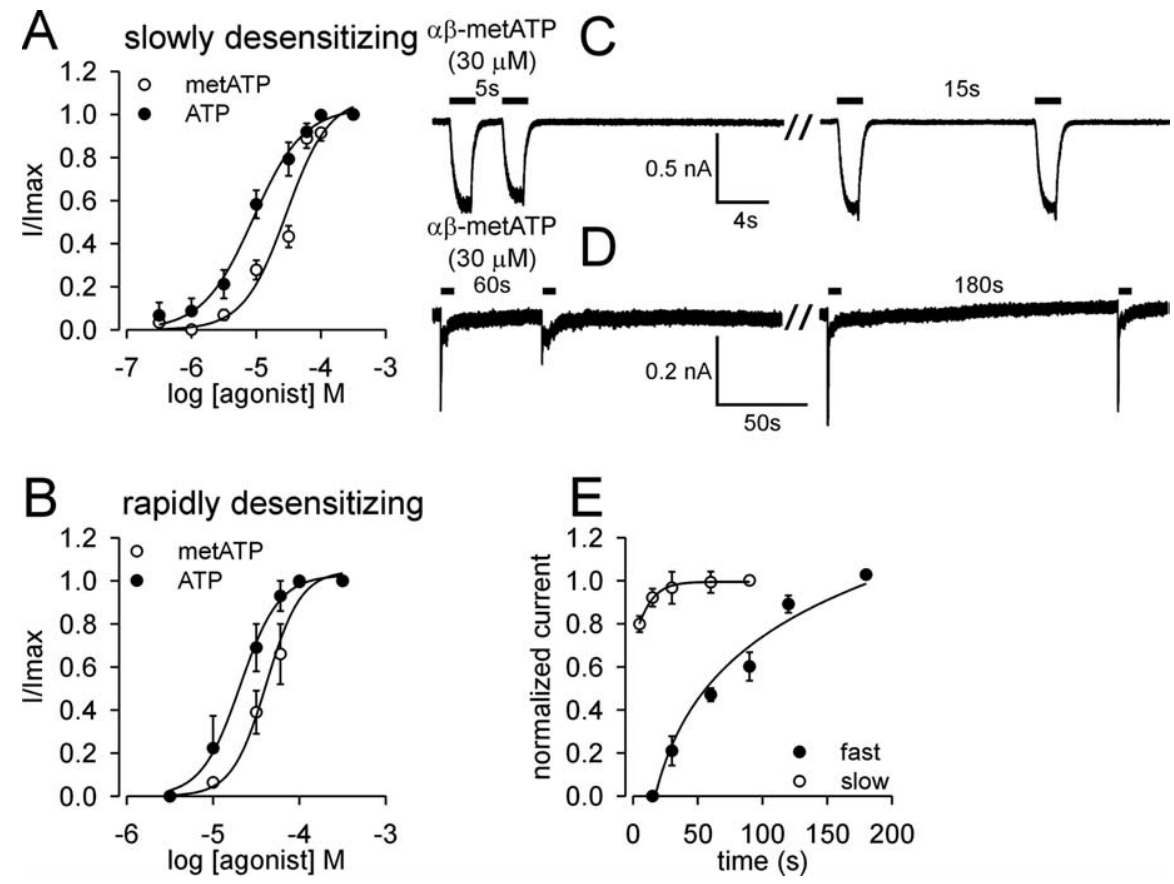

Figure 3. $\boldsymbol{A}, \boldsymbol{B}$, Dose-reponse relationship of slowly $(\boldsymbol{A})$ and rapidly $(\boldsymbol{B})$ desensitizing currents in response to application of $\alpha, \beta$-metATP or ATP. ATP (filled circles) was more potent than $\alpha, \beta$-metATP (open circles) with $\mathrm{EC}_{50}$ values of $44.6 \pm 4 \mu \mathrm{m}$ ( $n=$ 17) and 17.2 $\pm 3 \mu \mathrm{M}(n=11)$, respectively, for the slowly desensitizing current. Similarly, ATP was more potent than $\alpha, \beta$ metATP with $\mathrm{EC}_{50}$ values of $36.6 \pm 5 \mu \mathrm{m}(n=3)$ and $20.2 \pm 4 \mu \mathrm{m}(n=4)$, respectively, for the fast desensitizing current. I//max, Proportion of maximal current. $\boldsymbol{C}, \boldsymbol{D}$, Recovery kinetics for the slowly $(\boldsymbol{C})$ and rapidly $(\boldsymbol{D})$ desensitizing currents by varying the interapplication intervals of $\alpha, \beta$-metATP $(30 \mu \mathrm{M})$. $\boldsymbol{E}$, Recovered current fractions were fitted with a single exponential. Although the slow current (open circle) minimally desensitized and recovered rapidly with a constant of $10.8 \pm 5.7 \mathrm{~s}(n=3)$, the fast desensitizing current (filled circle) recovered significantly slower with a constant of $45 \pm 3 \mathrm{~s}(n=3 ; p<0.001)$.

$300 \mu \mathrm{M}$. As shown in Figure 3, $A$ and $B$, both $\alpha, \beta$-metATP- and ATP-activated currents were concentration dependent for both the slowly desensitizing and rapidly (fast) desensitizing currents. The $\mathrm{EC}_{50}$ values for $\alpha, \beta$-metATP and ATP for the slowly desensitizing current were $44.6 \pm 4 \mu \mathrm{M}(n=17)$ and $17.2 \pm 3 \mu \mathrm{M}(n=$ $11)$, respectively $(p<0.001)$. The $\mathrm{EC}_{50}$ values for $\alpha, \beta$-metATP and ATP for the rapidly desensitizing current were $36.6 \pm 5 \mu \mathrm{M}$ $(n=3)$ and $20.2 \pm 4 \mu \mathrm{M}(n=4)$, respectively $(p<0.05)$. ATP was found to be significantly more potent than $\alpha, \beta$-metATP for activation of the two kinetically distinct currents. To further examine whether ATP activates other P2 receptors, we applied maximal concentrations of $\alpha, \beta$-metATP $(300 \mu \mathrm{M})$ or ATP (300 $\mu \mathrm{M})$ to some neurons. ATP produced a $43.4 \pm 5.5 \%(n=6 ; p<$ 0.001 ) greater peak current than did $\alpha, \beta$-metATP for the slowly desensitizing current. In contrast, $\alpha, \beta$-metATP and ATP evoked similar peak current for the fast desensitizing current $(4.7 \pm 1.2 \%$; $n=4 ; p>0.05)$. Therefore, the greater potency of ATP relative to $\alpha, \beta$-metATP, and activation of other $\mathrm{P} 2$ receptors, appears to contribute to the greater slowly desensitizing current observed with ATP. However, the greater potency of ATP relative to $\alpha, \beta$-metATP accounts for the larger fast desensitizing current described after administration of ATP.

Recovery kinetics

To further characterize the $\alpha, \beta$-metATPevoked responses, we examined the recovery kinetics from desensitization of $\alpha, \beta$ metATP-elicited currents in principal current types found in LS neurons (slowly desensitizing) and TL neurons (fast/mixed desensitizing currents). The application duration remained the same (4s) in these experiments, but the application interval was increasingly extended, and the fraction of current in response to the second application of $\alpha, \beta$-metATP relative to the first application was plotted against time using a single-exponential fit. The slowly desensitizing current showed little decay and recovered rapidly (Fig. 3C), whereas the fast desensitizing component required 3 min for complete recovery (Fig. $3 D$ ). Based on single-exponential fitting (Fig. $3 E)$, the slowly desensitizing current recovered significantly faster than the rapidly desensitizing current [time constants of $10.8 \pm 5.7 \mathrm{~s}(n=3)$ and $45.5 \pm 3 \mathrm{~s}(n=$ 3 ), respectively; $p<0.001]$. Because rapidly and slowly desensitizing currents were rarely seen in LS and TL bladder neurons, respectively, we did not systematically examine their recovery kinetics.

\section{Antagonism of $\alpha, \beta$-metATP-evoked \\ currents by selective antagonists}

To facilitate the construction of dose-inhibition relationships for antagonists, we examined their effects using LS neurons because they showed a higher frequency of response than TL neurons. Once $\mathrm{IC}_{50}$ values were determined, excess concentrations of antagonist were used to examine $\alpha, \beta$-metATP-evoked currents. To confirm that $\alpha, \beta$-metATPevoked currents were mediated through $\mathrm{P} 2 \mathrm{X}$ receptors, we applied trinitrophenyl-ATP (TNP-ATP), a selective homomeric $\mathrm{P} 2 \mathrm{X}_{1}$, homomeric $\mathrm{P}_{2} \mathrm{X}_{3}$, and heteromeric $\mathrm{P} 2 \mathrm{X}_{2 / 3}$ receptor antagonist (Virginio et al., 1998). In the presence of TNP-ATP, the $\alpha, \beta$-metATP-mediated slowly desensitizing current was dosedependently antagonized (Fig. $4 \mathrm{~A}, \mathrm{C}$ ); the $\mathrm{IC}_{50}$ value of the antagonist was $20.1 \pm 6 \mathrm{nM}(n=5)$. A317491, a potent and selective homomeric $\mathrm{P} 2 \mathrm{X}_{3}$ and heteromeric $\mathrm{P} 2 \mathrm{X}_{2 / 3}$ receptor antagonist (Jarvis et al., 2002), also attenuated the current (Fig. 4B) in a dose-dependent manner $\left(\mathrm{IC}_{50}, 51.3 \pm 18.8 \mathrm{~nm} ; n=3\right.$ ) (Fig. 4C). However, in contrast to TNP-ATP, which at the greatest concentration blocked all of the $\alpha, \beta$-metATP-mediated current ( $1 \mu \mathrm{M}$ TNP-ATP; $98.4 \pm 1 \%$ ), A317491 only attenuated $34.9 \pm 10 \%$ of the control $\alpha, \beta$-metATP-evoked current at the greatest concentration tested $(10 \mu \mathrm{M})$. To confirm that the slowly desensitizing 
current produced by $\alpha, \beta$-metATP was mediated by heteromeric $\mathrm{P} 2 \mathrm{X}_{2 / 3}$ receptors, we also applied TNP-ATP $(100 \mu \mathrm{M})$ to every cell that was tested with A317491. Consistent with the description above, TNPATP antagonized almost all of the $\alpha, \beta$ metATP-evoked current, whereas A317491 only partially blocked the current (Fig. $4 A, B)$. Both TNP-ATP and A317491 completely and reversibly inhibited the fast desensitizing current in all five neurons tested (Fig. 4D,E). Therefore, the slowly and rapidly desensitizing currents studied here are likely to be mediated through heteromeric $\mathrm{P}_{2} \mathrm{X}_{2 / 3}$ and homomeric $\mathrm{P}_{2} \mathrm{X}_{3}$ receptors, respectively.

\section{Characterization of proton-sensitive} currents in bladder sensory neurons ATP is an acid, and although $1 \mathrm{mM}$ ATP did not change the $\mathrm{pH}$ of external solution buffered with $10 \mathrm{mM}$ HEPES, lowering the buffering capacity of the external solution to $0.05 \mathrm{~mm}$ unmasked the acidic nature of ATP (Fig. 5J). Considering the potential of ATP to briefly acidify the extracellular space when released, it is possible that bladder afferents may also respond to protons. Therefore, we challenged with protons bladder sensory neurons that were tested previously for purinergic responsiveness.

\section{LS bladder neurons}

Application of $\mathrm{pH} 5$ caused an inward current in 42 of $54(77.8 \%)$ LS bladder neurons tested (Fig. 5). We could differentiate transient and sustained currents, with the majority of cells expressing both types in response to protons. Based on activation and desensitization kinetics, we separated transient currents into rapidly and slowly desensitizing currents. Nine of 42 LS bladder neurons $(21.4 \%)$ expressed fast currents, all of which displayed two peaks with two distinct activation and desensitization time constants $(p<0.01)$ (Fig. 5A, Table 3). Accordingly, we termed the first and second rapidly desensitizing currents fast and intermediate, respectively, to distinguish them from the slowly desensitizing current. An additional 13 of 42 (31\%) proton-sensitive LS bladder neurons showed predominantly slowly activating and slowly desensitizing currents (Fig. $5 B)$. In the remaining 20 of $42(47.6 \%)$ neurons, protons triggered mixed transient and sustained currents (Fig. 5C). The desensitization kinetics of various proton-induced currents is summarized in Table 3. Current densities for the fast, intermediate, and slowly desensitizing and sustained components were $56.4 \pm 10,57.8 \pm 11,52.2 \pm 15.5$, and $86.1 \pm 16 \mathrm{pA} / \mathrm{pF}$, respectively.

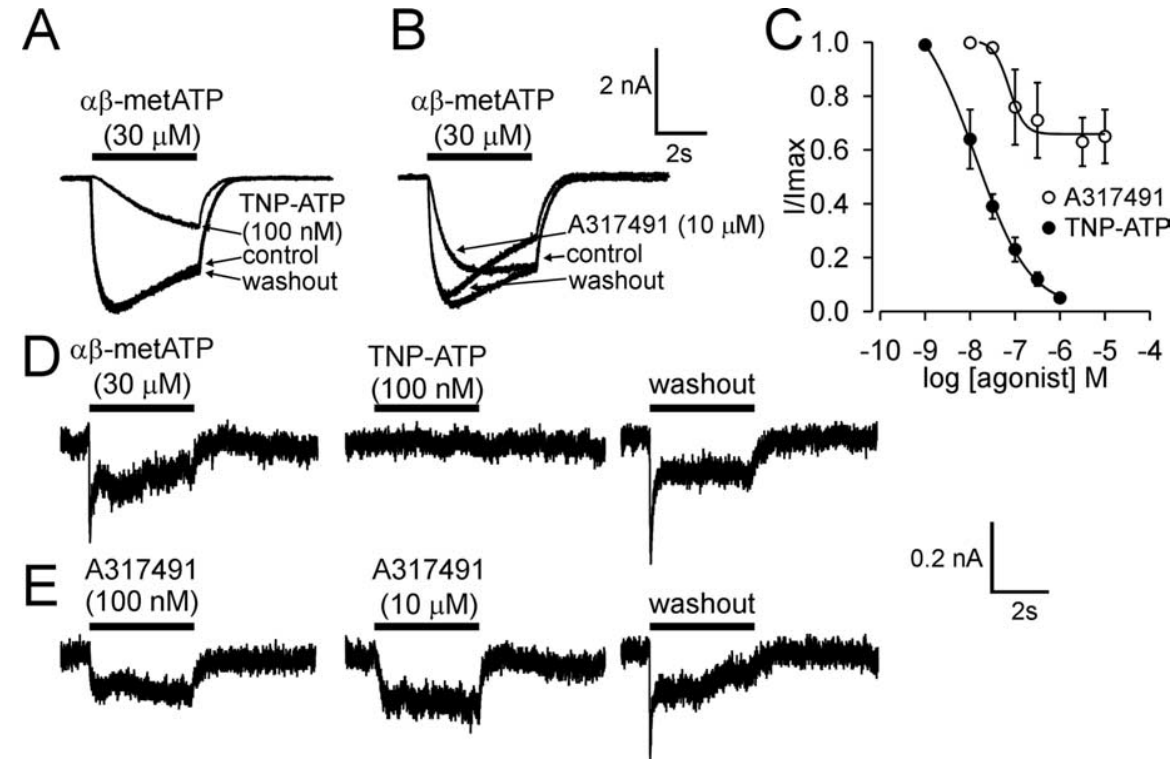

Figure 4. Antagonism of $\alpha, \beta$-metATP-evoked currents. $\boldsymbol{A}$, The $\alpha, \beta$-metATP-evoked slowly desensitizing current was significantly attenuated in the presence of TNP-ATP. The inhibition was reversible with complete recovery after washout. $\boldsymbol{B}$, In the same neuron, A317491 failed to completely antagonize the $\alpha, \beta$-metATP-evoked current. The partial inhibition was completely reversible. C, TNP-ATP completely abolished the $\alpha, \beta$-metATP-evoked current with an IC ${ }_{50}$ value of $20.1 \pm 6 \mathrm{~nm}(n=5)$, whereas A317491 only partially blocked the $\alpha, \beta$-metATP-evoked current $\left(\mathrm{IC}_{50}, 51.3 \pm 18.8 \mathrm{~nm} ; n=3\right)$. I/Imax, Proportion of maximal current. $\boldsymbol{D}$, Similarly, the $\alpha, \beta$-metATP-evoked fast desensitizing current (left trace) was completely inhibited by TNP-ATP (middle trace) and recovered after washout (right trace). $\boldsymbol{E}$, In the same cells $(n=5), A 317491$ at $100 \mathrm{~nm}$ (left trace) and $10 \mu \mathrm{m}$ (middle trace) completely antagonized the $\alpha, \beta$-metATP-evoked current with full recovery after washout (right trace). Note that the sustained component was unaffected by $\mathrm{A} 317491$.
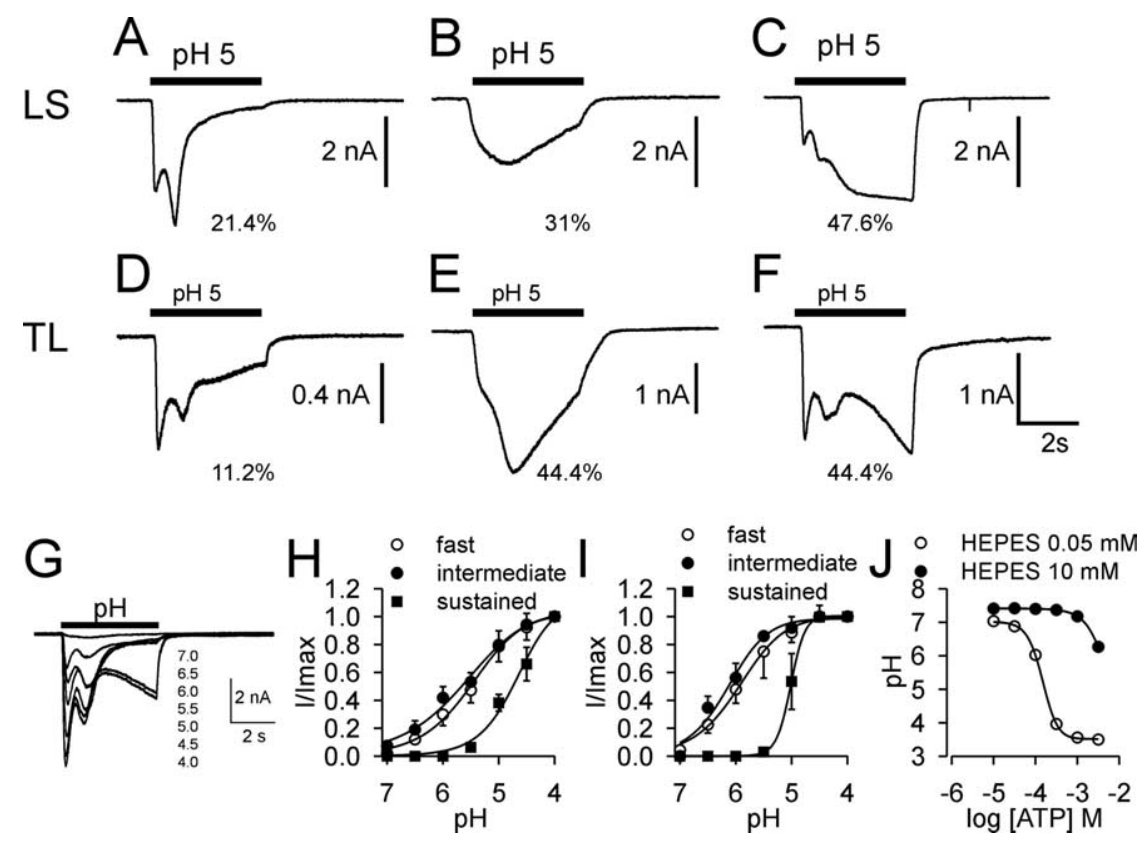

Figure 5. Proton-evoked currents in bladder sensory neurons. Protons ( $\mathrm{pH} 5$ ) produced a spectrum of currents with distinct desensitizing kinetics: fast, intermediate, and slowly desensitizing and sustained. Three current patterns were identified in LS neurons: fast and intermediate desensitizing $(\boldsymbol{A})$, slowly desensitizing $(\boldsymbol{B})$, and fast and intermediate desensitizing $(\boldsymbol{C})$, followed by sustained. Similarly, fast and intermediate desensitizing $(\boldsymbol{D})$, slowly desensitizing $(\boldsymbol{E})$, fast and intermediate desensitizing $(\boldsymbol{F})$ followed by a sustained current, was found in TL neurons. Protons produced progressively greater currents in a concentration-dependent manner as shown in $\mathbf{G} . \boldsymbol{H}, \boldsymbol{I}, \mathrm{pH}$ response relationships for various proton-evoked currents in $L S(\boldsymbol{H})$ and $\mathrm{TL}(\boldsymbol{I})$ neurons. Fast $(\boldsymbol{O})$, intermediate $(\bigcirc)$, and sustained $(\square)$ currents were pH dependent with $\mathrm{EC}_{50}$ values of $5.79 \pm 0.27(n=12), 5.48 \pm 0.45(n=12)$, and $4.51 \pm 0.1(n=8)$, respectively, for LS neurons. Similarly, the $\mathrm{EC}_{50}$ values in TL neurons for fast, intermediate, and sustained currents were $5.89 \pm 0.20(n=7), 6.19 \pm 0.24$ $(n=7)$, and $4.73 \pm 0.2(n=3)$, respectively. The $\mathrm{EC}_{50}$ values of the sustained component of the current were significantly lower than those for fast and intermediate currents $(p<0.05)$. I/Imax, Proportion of maximal current. J, ATP concentration-pH relationship. In 10 mm HEPES-buffered solution (filled circle; $n=3$ ), ATP up to $1 \mathrm{~mm}$ did not change the $\mathrm{pH}$, whereas ATP produced a concentrationdependent drop in pH in 0.05 mм HEPES-buffered solution (open symbol; $n=3$ ). 
Table 3. Summary of proton-evoked current kinetics in bladder sensory neurons

\begin{tabular}{|c|c|c|}
\hline & \multicolumn{2}{|l|}{ pH5 } \\
\hline & $\operatorname{ttp}(\mathrm{ms})$ & $\operatorname{tau}(\mathrm{ms})$ \\
\hline \multicolumn{3}{|l|}{ LS } \\
\hline Fast & $318 \pm 20$ & $311 \pm 70$ \\
\hline Intermediate & $1056 \pm 111$ & $592 \pm 84$ \\
\hline Slow & $1784 \pm 183$ & $1433 \pm 331$ \\
\hline Sustained & $3935 \pm 66$ & $\mathrm{n} / \mathrm{a}$ \\
\hline \multicolumn{3}{|l|}{$\mathrm{TL}$} \\
\hline Fast & $370 \pm 28$ & $266 \pm 37$ \\
\hline Intermediate & $1326 \pm 98$ & $652 \pm 46$ \\
\hline Slow & $1603 \pm 104$ & $4309 \pm 778$ \\
\hline Sustained & $3892 \pm 88$ & $\mathrm{n} / \mathrm{a}$ \\
\hline
\end{tabular}

ttp, Time to peak; $n / a$, not applicable.

A - lumbosacral
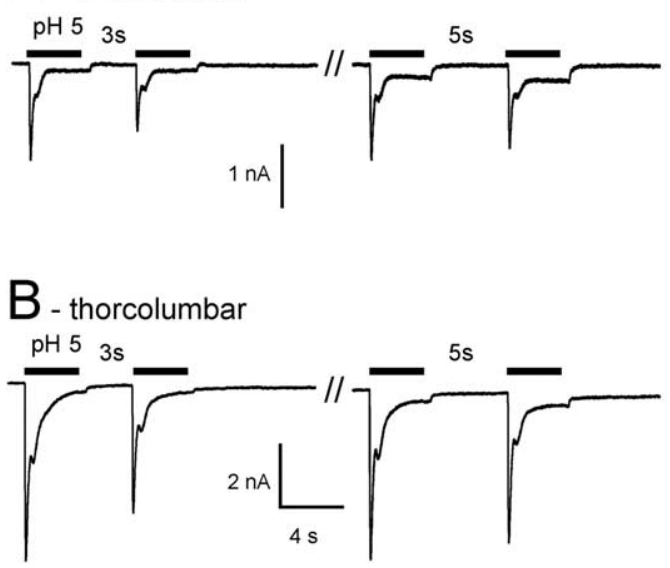
respectively. Both currents recovered partially from desensitization after $3 \mathrm{~s}$ (left pair of traces) and almost completely after $5 \mathrm{~s}$ (right pair of traces). The recovery kinetics of both current types followed a single-exponential function in $L S(\boldsymbol{C})$ and TL (D) neurons with time constants (fast and intermediate, respectively) of $0.65 \pm 0.18 \mathrm{~s}(n=4)$ and $1.1 \pm 0.21 \mathrm{~s}(n=4)$ for $\mathrm{LS}$ neurons and $0.56 \pm 0.13 \mathrm{~s}(n=3)$ and $1.26 \pm 0.37 \mathrm{~s}(n=3)$ for TL counterparts.

\section{TL bladder neurons}

A similar fraction of TL bladder neurons (45 of 52; $86.5 \%$ ) responded to protons. Based on kinetics, we differentiated transient and sustained currents (Fig. 5D-F). Five (11.2\%) neurons expressed transient currents with fast desensitization (Fig. 5D), and an additional 20 (44.4\%) neurons responded with only slowly desensitizing currents (Fig. 5E). The remaining 20 cells (44.4\%) expressed mixed transient and sustained currents (Fig. $5 F)$. Although no differences in the fraction of neurons with distinct kinetics and kinetics of fast and intermediate desensitizing currents were found in LS neurons compared with their TL counterparts, the slow current in TL neurons desensitized significantly slower than in LS neurons $(p<0.001)$. Current densities were $48.2 \pm 10,59 \pm 12,74.8 \pm 15$, and $30.3 \pm 7 \mathrm{pA} / \mathrm{pF}$ for fast, intermediate, and slowly desensitizing and sustained components, respectively. Whereas the current densities of fast, intermediate, and slowly desensitizing components did not differ, the sustained current density was significantly less in TL than in LS bladder neurons $(p<0.001)$.
pH dependency

Recent evidence suggests that homomeric ASIC1a and ASIC3 channels are most sensitive to protons (Benson et al., 2002; Hesselager et al., 2004). These homomeric channels are typically characterized by rapid desensitization kinetics similar to the fast and intermediate desensitizing currents described above. To further differentiate proton-evoked currents, we explored proton sensitivity by investigating the $\mathrm{pH}$ response relationship in neurons that predominantly expressed fast and intermediate desensitizing currents (Fig. 5G). Lowering the $\mathrm{pH}$ from 7 to 4 evoked increasingly larger currents in LS bladder neurons with $\mathrm{pH}_{50}$ values of $5.79 \pm 0.27(n=12)$ and $5.48 \pm 0.45(n=12)$ for fast and intermediate desensitizing currents, respectively (Fig. $5 H$ ). Similarly, progressively larger currents were evoked by increasing the concentration of protons in TL neurons, with $\mathrm{pH}_{50}$ values of $5.89 \pm 0.20(n=7)$ and $6.19 \pm 0.24(n=$ 7) for fast and intermediate desensitizing currents, respectively (Fig. 5I). pH sensitivity did not differ for fast and intermediate desensitizing proton-gated currents in either LS or TL neurons. The sustained proton-activated current in both LS and TL neurons, however, had a low $\mathrm{pH}$ threshold that was apparent as the $\mathrm{pH}$ was decreased to $\leq 5.5 ; \mathrm{pH}_{50}$ values for LS and TL bladder neurons were $4.51 \pm 0.1(n=$ $8)$ and $4.73 \pm 0.2(n=3)$, respectively. Although the $\mathrm{pH}_{50}$ values of the sustained component did not differ between LS and TL neurons, they were significantly lower than the $\mathrm{pH}_{50}$ values determined for the fast and intermediate desensitizing currents described above $(p<0.05)$.

\section{Recovery kinetics}

We next examined the recovery kinetics of transient proton-evoked currents from desensitization. As described above, we varied the interapplication duration and measured the fractions of current recovered over time. As shown in Figure 6, both fast and intermediate desensitizing currents in LS and TL neurons recovered rapidly and almost completely from desensitization within $5 \mathrm{~s}$. The kinetics of recovery followed a single-exponential function with time constants of $0.65 \pm 0.18 \mathrm{~s}$ $(n=4)$ and $1.1 \pm 0.21 \mathrm{~s}(n=4)$ for fast and intermediate desensitizing currents, respectively, in LS neurons (Fig. 6C). Similarly, the recovery time constants for fast and intermediate desensitization currents were $0.56 \pm 0.13 \mathrm{~s}(n=3)$ and $1.26 \pm 0.37 \mathrm{~s}(n=3)$ in TL neurons (Fig. $6 \mathrm{D}$ ). The recovery kinetics for fast and intermediate desensitizing currents did not differ and were similar for LS and TL neurons.

\section{Antagonism of proton-evoked currents by amiloride and capsazepine}

To determine whether proton-evoked currents were mediated through ASICs, we applied amiloride $(200 \mu \mathrm{M})$, a nonselective ASIC blocker (McCleskey and Gold, 1999). In the presence of amiloride, proton-evoked fast and intermediate desensitizing currents were reduced to $1.7 \pm 0.7 \%(n=5)$ and $9.8 \pm 3.2 \%(n=$ 5 ) of control, respectively, indicating that transient protonevoked currents were mediated by ASICs. Interestingly, the sustained component of the current was also inhibited to $26.4 \pm 8 \%$ 

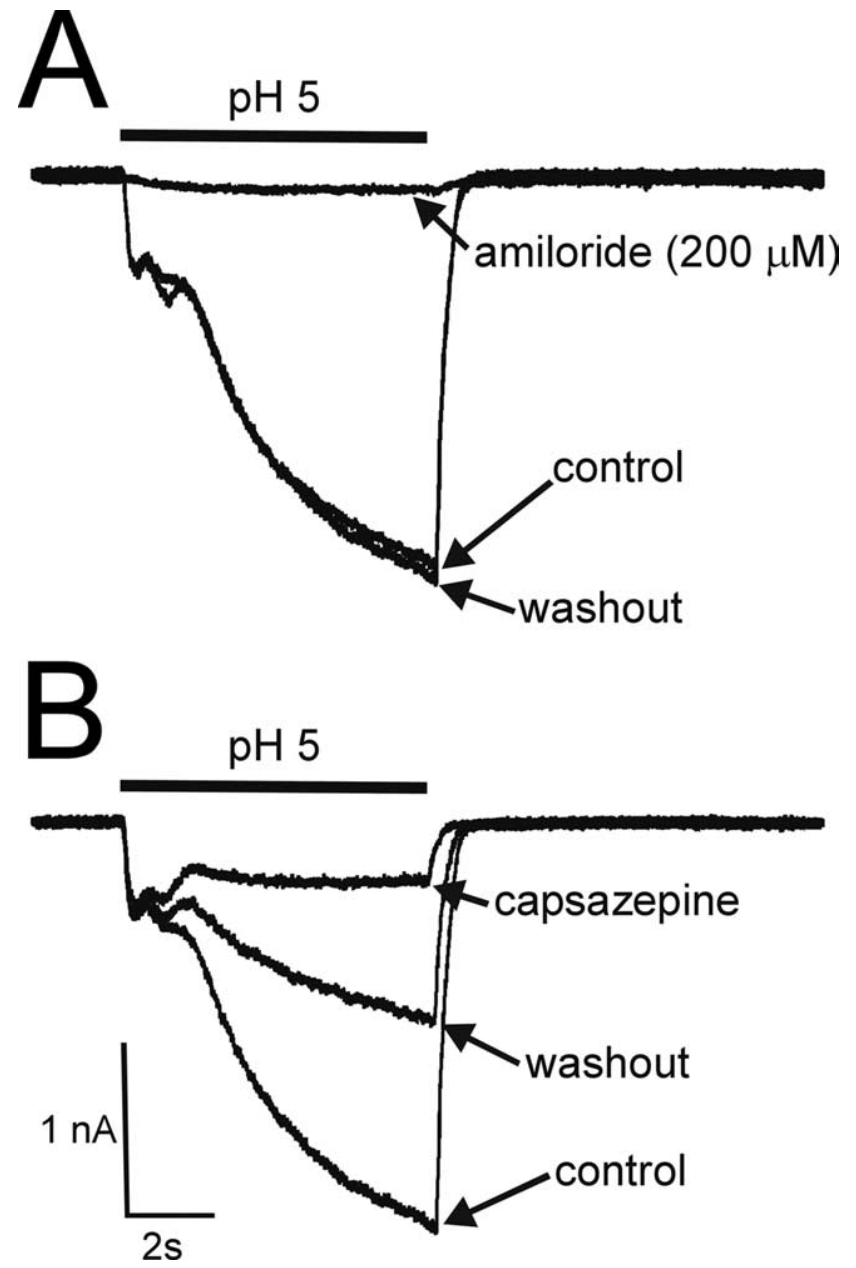

Figure 7. Antagonism of proton-evoked currents by amiloride and capsazepine. $A$, Fast and intermediate desensitizing and sustained currents produced by $\mathrm{pH} 5$ were reduced to $1.7 \pm 0.7$, $9.8 \pm 3.2$, and $26.4 \pm 8 \%(n=5)$ of control currents in the presence of amiloride, respectively. The inhibition was reversible after washout. $\boldsymbol{B}$, In the same neurons, capsazepine inhibited the sustained current evoked by pH 5 to $31 \pm 13.5 \%$ of control without affecting the fast and intermediate desensitizing currents. Only partial recovery from capsazepine-produced inhibition was observed. All traces were taken from the same neuron.

$(n=5)$ of control. All three components recovered completely after washout (Fig. 7A). Previous studies have shown that protons at high concentrations can activate TRPV1 channels and could account for the sustained component that we saw when $\mathrm{pH} 5$ was used. Therefore, we applied the TRPV1 receptor antagonist capsazepine (Dickenson and Dray, 1991) to determine whether the sustained component of the current was mediated through TRPV1 channels in the same neurons. Application of capsazepine $(100 \mu \mathrm{M})$ reduced the sustained current to $31 \pm 13.5 \%$ of control without affecting the transient currents, suggesting that the sustained component is mediated, in part, through TRPV1 channels (Fig. 7B).

\section{Effects of capsaicin}

Because protons can activate TRPV1 channels, capsaicin was used to further confirm the presence of functional TRPV1 receptors on bladder sensory neurons that were tested previously with purinergic agonists and protons. Capsaicin $(1 \mu \mathrm{M})$ evoked a persistent inward current in 49 of $54(90.7 \%)$ LS neurons with a current density of $129.6 \pm 17 \mathrm{pA} / \mathrm{pF}$ (Fig. $8 D$ ). All protonsensitive neurons (42 of 42 ) that displayed a transient compo- nent(s) were also responsive to capsaicin, suggesting colocalization of functional ASIC and TRPV1 receptors in LS bladder sensory neurons. In addition, all proton-sensitive neurons with a sustained current $(48 \% ; 22$ of 42$)$ responded to capsaicin. Seventy-six percent (41 of 54) of LS neurons responded to $\alpha, \beta$ metATP as well as protons and capsaicin, suggesting a high degree of colocalization of functional P2X, ASIC, and TRPV1 receptors on these neurons (Fig. 8). The percentage of bladder sensory neurons that responded to $\alpha, \beta$-metATP, protons, and capsaicin is summarized in Table 4.

Similarly, capsaicin produced an inward current in 48 of 52 (92.3\%) TL neurons with a current density of $86.9 \pm 11 \mathrm{pA} / \mathrm{pF}$ (Fig. $8 H$ ). Although the percentage of capsaicin-sensitive neurons did not differ between LS and TL bladder sensory neurons, the capsaicin-evoked current density was significantly less in TL neurons than in LS counterparts $(p<0.05)$, consistent with the proton-evoked sustained current being mediated through TRPV1 channels. Similar to LS neurons, all proton-sensitive TL neurons exhibiting a sustained component (44\%; 20 of 45$)$ also responded to capsaicin. Almost all proton-sensitive TL neurons (44 of 45) that had a transient component(s) also responded to capsaicin, suggesting colocalization of ASIC and TRPV1 receptors. A significantly smaller proportion of TL neurons (48.1\%; 25 of 52) responded to $\alpha, \beta$-metATP as well as protons and capsaicin, suggesting a lesser degree of colocalization of P2X, ASIC, and TRPV1 channels in TL than in LS bladder neurons $(p<$ $0.05)$. We verified immunohistochemically the coexpression of $\mathrm{P} 2 \mathrm{X}$ and TRPV1 receptors on bladder sensory neurons that were retrogradely labeled from the bladder by Fluorogold (Fig. 9A,B) but did not attempt to quantify the percentages of receptor expression or coexpression. Consistent with the functional evidence for colocalization of $\mathrm{P} 2 \mathrm{X}$ receptors and TRPV1 channels, $\mathrm{P}_{2} \mathrm{X}_{2}$ and $\mathrm{P} 2 \mathrm{X}_{3}$ subunits (Fig. $9 A$ ) or $\mathrm{P} 2 \mathrm{X}_{2}$ and TRPV1 channels (Fig. 9B) were coimmunostained within the same bladder neurons.

\section{IB4 labeling}

Because binding of IB4 is considered to indicate the absence of myelination (Chen et al., 2003), we estimated the number of neurons that give rise to unmyelinated axons in LS and TL DRGs. One coverslip from each rat $(n=3)$ was selected randomly for cell counting. In control experiments, the binding of IB4 was considered specific because preincubation with unconjugated IB4 $(0.2 \mathrm{mg} / \mathrm{ml})$ blocked all binding of the conjugated form (data not shown). Of 2267 LS and 3613 TL neurons, 1071 and 1867, respectively, bound IB4. Thus, IB4-positive neurons comprised $48.8 \pm 2.5 \%(n=3)$ and $54.3 \pm 3.8 \%(n=3)$ of all LS and TL DRG neurons in the samples studied, respectively $(p>0.05)$. Approximately $50-70$ and $96 \%$ of rat bladder pelvic and hypogastric/splanchnic afferents, respectively, have slow conduction velocities consistent with the absence of myelination (Nadelhaft and Vera, 1991; Sengupta and Gebhart, 1994; Shea et al., 2000). To characterize bladder sensory neurons further, we applied IB4 after examination of neurons as described above (Fig. 9C). Sixtyone percent (33 of 54) of LS bladder neurons and 84.6\% (44 of $52)$ of TL bladder neurons were positive for IB $4\left(\chi^{2}=6.2 ; p<\right.$ 0.05 ). Sixty percent ( 30 of 50 ) of $\alpha, \beta$-metATP-sensitive LS neurons and $84.6 \%$ (22 of 26 ) of $\alpha, \beta$-metATP-sensitive TL neurons stained for IB4 $\left(\chi^{2}=0.553 ; p=0.4\right)$, revealing that not all P2X receptor-expressing cells were IB4 positive. Similarly, most but not all neurons responding to protons were IB4 positive; 31 of 42 $(73.8 \%)$ and 38 of $45(84.4 \%)$ proton-sensitive LS and TL neurons, respectively, were IB4 positive $\left(\chi^{2}=0.9 ; p=0.3\right)$. Finally, 

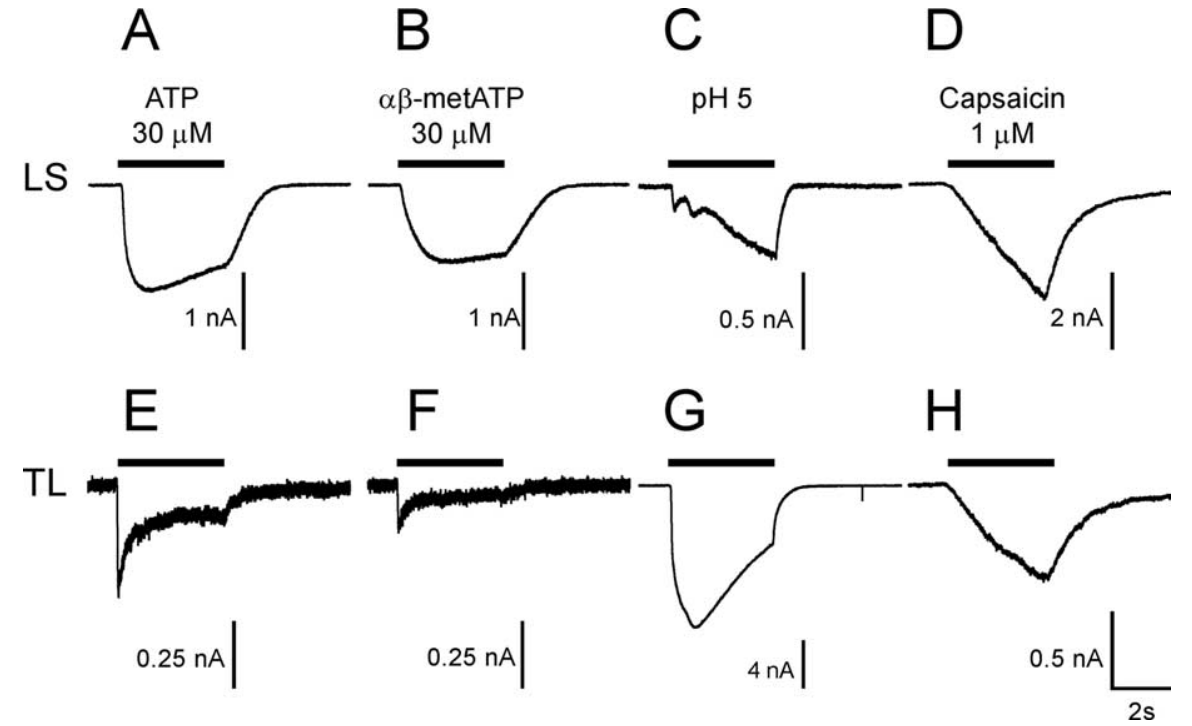

Figure 8. Sensitivity to purinergic agonists, protons, and capsaicin in bladder sensory neurons. Sequential application of ATP $(\boldsymbol{A}), \alpha, \beta$-metATP $(\boldsymbol{B})$, pH $5(\boldsymbol{C})$, and capsaicin $(\boldsymbol{D})$ to the same neuron evoked inward currents in $75.9 \%$ (41 of 52$)$ of $\mathrm{LS}$ neurons. Similarly, $\operatorname{ATP}(\boldsymbol{E}), \alpha, \beta$-metATP $(\boldsymbol{F})$, pH $5(\boldsymbol{G})$, and capsaicin $(\boldsymbol{H})$ produced inward currents in $48.1 \%(25$ of 52$)$ of TL neurons.

31 of $49(63.3 \%)$ and 40 of $48(83.3 \%)$ capsaicin-sensitive LS and TL neurons, respectively, stained with IB4 $\left(\chi^{2}=4.0 ; p<0.05\right)$.

\section{Discussion}

The pelvic and hypogastric/lumbar splanchnic innervations of the bladder subserve different functions (see Introduction). Recent reports have implicated P2X and TRPV1 receptors in micturition (Cockayne et al., 2000; Birder et al., 2002), and we compared in the present study responses of TL and LS bladder sensory neurons to purinergic agonists, protons, and capsaicin. In addition to similarities, we noted differences between the two bladder neuron populations: (1) nearly all LS but only $50 \%$ of TL neurons responded to $\alpha, \beta$-metATP; (2) LS and TL neurons exhibited slowly and mixed desensitizing currents, respectively, with LS neurons expressing greater slowly desensitizing current density than TL counterparts; and (3) most bladder neurons also responded to protons and capsaicin, but significantly more LS than TL neurons responded to $\alpha, \beta$-metATP, protons, and capsaicin. We also noted differences in size between TL and LS neurons and between the density of innervation by the two pathways, all of which support differential transmission of sensory information in bladder pelvic and hypogastric/lumbar splanchnic afferent pathways

Despite the importance of the extrinsic innervation in sensation and micturition (Andersson, 2002), virtually no information is available about the relative densities of pelvic and hypogastric/ lumbar splanchnic innervation of the bladder. Acknowledging that we may have underestimated bladder innervation because the entire bladder was not injected with DiI, we found twice as many neurons projecting through the pelvic nerves than the hypogastric/lumbar splanchnic nerves.

Most LS bladder neurons were small or medium in size based on capacitance, a finding consistent with an immunohistochemical study of S1 bladder neurons (Yohimura et al., 2003) and electrophysiological evidence that 50$70 \%$ of pelvic nerve bladder afferents conduct in the C-fiber range (Sengupta and Gebhart, 1994; Shea et al., 2000). In contrast, we found that TL bladder neurons were medium to large in size, although $>90 \%$ of hypogastric/lumbar splanchnic nerve fibers are unmyelinated based on conduction velocity (Nadelhaft and Vera, 1991). In addition, although $\mathrm{P}_{2} \mathrm{X}_{3}$ and TRPV1 are considered to be expressed predominantly on small DRG neurons associated with nociceptors (Caterina et al., 1997, 2000; Vulchanova et al., 1998), the present results question the use of cell size as a surrogate index of axon myelination and reveal that many medium or large bladder sensory neurons also express functional $\mathrm{P}_{2} \mathrm{X}_{3}$ and TRPV1 receptors, emphasizing that, at least in visceral sensory neurons, cell diameter is an unreliable indicator of presumed function.

Because IB4 binding is considered a marker for neurofilamentnegative neurons associated with unmyelinated axons (Yoshimura et al., 2003), we stained recorded cells for IB4 (Chen et al., 2003). Approximately 50-70 and $96 \%$ of pelvic and hypogastric/lumbar splanchnic nerve bladder afferents, respectively, conduct in the C-fiber range (Nadelhaft and Vera, 1991; Sengupta and Gebhart, 1994; Shea et al., 2000), consistent with the absence of neurofilament staining in $\sim 70 \%$ of bladder LS neurons (Yoshimura et al., 2003). In support, we found that most TL (85\%) and LS (61\%) neurons bound IB4. Although these findings are consistent with physiological data, Yoshimura et al. (2003) reported that only $20 \%$ of LS bladder neurons bound IB4. The discrepancy may in part be attributable to technical differences; we noted significantly less staining of bladder neurons by FITC-IB4 compared with AlexaFluor 488-IB4 (at the same concentration). Despite the apparent higher sensitivity of AlexaFluor 488 -IB4, only $\sim 60 \%$ of $\alpha, \beta$-metATP-responsive LS bladder neurons bound IB4 in contrast to the $>90 \%$ of unlabeled, small-sized $\mathrm{P}_{2} \mathrm{X}_{3}$-immunoreactive DRG neurons reported to bind IB4 (Vulchanova et al., 1998). In further contrast, although nearly $90 \%$ of TL bladder neurons bound IB4, Su et al. (1986) reported that most TL neurons innervating the urinary tract were calcitonin generelated peptide immunoreactive. Thus, as appears true for P2X and TRPV1, IB4 may not reliably identify nonpeptidergic bladder neurons. These data highlight differences between bladder (visceral) and somatic sensory neurons, further supporting that visceral and somatic sensory neurons are functionally distinct (McMahon, 1997).

The homomeric $\mathrm{P}_{2} \mathrm{X}_{1}$, homomeric $\mathrm{P}_{2} \mathrm{X}_{3}$, and heteromeric $\mathrm{P}_{2} \mathrm{X}_{2 / 3}$ receptor agonist $\alpha, \beta$-metATP triggered a slowly desensitizing current in most LS neurons $(86 \%)$, consistent with a recent report (Zhong et al., 2003). Rapidly inactivating and mixed ki-

Table 4. Summary of bladder sensory neurons that respond to $\alpha, \beta$-metATP, protons, and capsaicin

\begin{tabular}{|c|c|c|c|c|c|c|c|}
\hline & $\alpha, \beta$-metATP & $\mathrm{H}^{+}$ & Capsaicin & $\alpha, \beta$-metATP and $\mathrm{H}^{+}$ & $\begin{array}{l}\alpha, \beta \text {-metATP } \\
\text { and capsaicin }\end{array}$ & $\mathrm{H}^{+}$and capsaicin & $\begin{array}{l}\alpha, \beta \text {-metATP, } \mathrm{H}^{+} \\
\text {and capsaicin }\end{array}$ \\
\hline LS & $92.6 \%(50 / 54)$ & $77.8 \%(42 / 54)$ & $90.7 \%(49 / 54)$ & $84 \%(42 / 50)$ & $98 \%(49 / 50)$ & $100 \%(42 / 42)$ & $75.9 \%(41 / 54)$ \\
\hline $\mathrm{TL}$ & $50 \%(26 / 52)^{*}$ & $86.5 \%(45 / 52)$ & $92.3 \%(48 / 52)$ & $100 \%(26 / 26)$ & $100 \%(26 / 26)$ & $97.8 \%(44 / 45)$ & $48.1 \%(25 / 52)^{*}$ \\
\hline
\end{tabular}

Data are a comparison between $L S$ and TL neurons $\left({ }^{*} p<0.05\right)$. 
netic currents were produced by $\alpha, \beta$ metATP in $<15 \%$ of LS neurons. In constrast, only one-half of TL bladder neurons studied expressed functional P2X receptors, revealing that $\mathrm{P} 2 \mathrm{X}$ receptors are differentially expressed in the two afferent bladder pathways. Furthermore, $\alpha, \beta$ metATP triggered rapidly inactivating or mixed currents in most of these TL neurons. The desensitization kinetics of mixed currents followed a double-exponential function, suggesting heterogeneous P2X receptor expression in the same neuron. Based on current kinetics and antagonism by TNP-ATP [a P2X $1, \mathrm{P}_{2} \mathrm{X}_{3}$, and $\mathrm{P} 2 \mathrm{X}_{2 / 3}$ receptor antagonist (Virginio et al., 1998)] and previous reports demonstrating (1) dependence on $\mathrm{P}_{2} \mathrm{X}_{3}$ for $\alpha, \beta$-metATP sensitivity (Cockayne et al., 2000), (2) high incidence of colocalization of $\mathrm{P}_{2} \mathrm{X}_{2}$ and $\mathrm{P} 2 \mathrm{X}_{3}$ (Vulchanova et al., 1997), and (3) absence of $\mathrm{P} 2 \mathrm{X} 1$ receptor transcripts in DRG neurons (Kobayashi et al., 2005), the present data suggest that activation of $\mathrm{P}_{2} \mathrm{X}_{2 / 3}$ receptors by $\alpha, \beta$-metATP produces the slowly desensitizing current. Additionally, both TNP-ATP and the $\mathrm{P}_{3}$ and $\mathrm{P} 2 \mathrm{X}_{2 / 3}$ receptor antagonist $\mathrm{A} 317491$ (Jarvis et al., 2002) completely antagonized the fast desensitizing current, suggesting that activation of homomeric $\mathrm{P} 2 \mathrm{X}_{3}$ receptors mediates the fast desensitizing current. However, even at high concentrations $(10 \mu \mathrm{M}), \mathrm{A} 317491$ only antagonized $\sim 30 \%$ of the slowly desensitizing current. This contrasts with a complete block of the fast desensitizing current at significantly lower concentrations (100 nM), consistent with previous data for the fast current (Jarvis et al., 2002). These findings in native bladder sensory neurons demonstrate greater inhibitory effects of

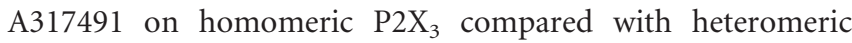
$\mathrm{P}_{2} \mathrm{X}_{2 / 3}$ receptors, consistent with data from heterologous expression systems (Jarvis et al., 2002), and clearly show a more striking difference of inhibitory effects on the kinetically distinct currents. Based on kinetic and pharmacological characteristics, LS bladder neurons express predominantly $\mathrm{P}_{2} \mathrm{X}_{2 / 3}$ receptors, whereas heterogeneous populations of homomeric $\mathrm{P}_{2} \mathrm{X}_{3}$ and heteromeric $\mathrm{P} 2 \mathrm{X}_{2 / 3}$ receptors are found in TL counterparts. Because (1) significantly more LS than TL neurons responded to purinergic agonists, (2) LS neurons expressed significantly greater peak current density (slow type) than TL counterparts, and (3) the differences in desensitization and recovery kinetics, we suggest that purinergic transmission under normal physiological conditions is predominantly conveyed through pelvic rather than the hypogastric/lumbar splanchnic afferents by activating heteromeric $\mathrm{P} 2 \mathrm{X}_{2 / 3}$ receptors.

Because ATP is acidic, ATP released in sufficient quantities could acidify the immediate microenvironment and activate P2X as well as proton-sensitive channels. In support, most $(>80 \%)$ $\alpha, \beta$-metATP-sensitive neurons also responded to protons, suggesting a high degree of colocalization of ASIC and P2X channels. ASIC channels are implicated because proton sensitivity of the cells is relatively high and amiloride, an ASIC channel antagonist (McCleskey and Gold, 1999), antagonized effects. Based on the presence of multiple components and complex current kinetics, our data suggest the existence of multiple ASIC subunits in the same cell. The transient currents had similar $\mathrm{pH}_{50}$ values, consistent with previous findings showing that most ASIC channels in vivo are heteromers that show no difference in proton sensitivity compared with homomeric forms (Benson et al., 2002; Hesselager et al., 2004). In contrast, the sustained component of the proton-gated current showed significantly lower $\mathrm{pH}_{50}$ compared with $\mathrm{pH}_{50}$ values determined for transient components and was partially antagonized by amiloride and capsazepine, a TRPV1 receptor antagonist (Dickenson and Dray, 1991). Although transient and sustained proton-activated currents were indiscriminately antagonized by amiloride, capsazepine selectively suppressed the sustained component. Based on lower proton sensitivity, current kinetics, and antagonism by capsazepine, activation of TRPV1 receptors, in part, accounts for the sustained current in bladder neurons.

Because TRPV1 receptors are important to bladder function (Caterina et al., 1997, 2000; Tominaga et al., 1998; Birder et al., 2002), we examined bladder neuron sensitivity to capsaicin. More than $90 \%$ of bladder neurons responded to capsaicin with a sustained current, confirming the presence of functional TRPV1 receptors, which have been documented immunohistochemically (Cockayne et al., 2000; Birder et al., 2002). One might expect bladder neurons that responded to capsaicin to also exhibit a sustained current to protons, but neither we nor others (Steen et al., 1992; Dirajlal et al., 2003) found such a relationship. Both the sustained proton-evoked current and capsaicin-activated peak current densities were greater in LS than in TL neurons. Moreover, significantly more LS neurons (76\%) responded to $\alpha, \beta$-metATP, protons, and capsaicin than did TL counterparts (48\%), suggesting a greater degree of P2X, ASIC, and TRPV1 receptor colocalization in 
LS than in TL bladder neurons. Consistent with these functional data, coexpression of the receptor proteins on bladder sensory neurons was also seen immunohistochemically.

\section{Significance of functional P2X, ASIC, and TRPV1 channel colocalization}

Release of ATP from the urothelium during bladder distension contributes to micturition (Cockayne et al., 2000; Vlaskovska et al., 2001), and Burnstock (1996) has suggested that ATP within hollow organs can mediate painful sensations. In support of the latter, significantly more ATP is released from urothelial cells in interstitial cystitis patients compared with normal subjects (Sun et al., 2001). The high degree of colocalization of functional P2X, ASIC, and TRPV1 channels in bladder neurons reported here suggests potential interaction/modulation and cotransmission by ATP and protons. ATP is acidic, and the potential release of three additional protons through the hydrolysis of ATP to adenine by ectonucleotidases could further acidify the microenvironment (Robergs et al., 2004). Of the seven known P2X receptor subunits, heteromeric $\mathrm{P}_{2} \mathrm{X}_{2 / 3^{-}}$or homomeric $\mathrm{P} 2 \mathrm{X}_{2}$-mediated currents are potentiated by protons, whereas the homomeric $\mathrm{P}_{2} \mathrm{X}_{3}$-mediated current is inhibited by acidic $\mathrm{pH}$ (Stoop et al., 1997). Accordingly, we propose that ATP, by virtue of its acidic nature, could also activate ASIC and TRPV1 channels. The net effect would result in larger currents associated with greater depolarization and an increase in action potential number that may partly account for altered sensory transmission and sensitization of the bladder after cystitis.

\section{References}

Andersson KE (2002) Bladder activation: afferent mechanisms. Urology 59:43-50.

Applebaum AE, Vance WH, Coggeshall RE (1980) Segmental localization of sensory cells that innervate the bladder. J Comp Neurol 192:203-209.

Benson CJ, Xie J, Wemmie JA, Price MP, Henss JM, Welsh MJ, Snyder PM (2002) Heteromultimers of DEG/ENaC subunits form $\mathrm{H}^{+}$-gated channels in mouse sensory neurons. Proc Natl Acad Sci USA 99:2338-2343.

Birder LA, Nakamura Y, Kiss S, Nealen ML, Barrick S, Kanai AJ, Wang E, Ruiz G, de Groat WC, Apodaca G, Watkins S, Caterina MJ (2002) Altered urinary bladder function in mice lacking the vanilloid receptor TRPV1. Nat Neurosci 5:856-860.

Brady CM, Apostolidis AN, Harper M, Yiangou Y, Beckett A, Jacques TS, Freeman A, Scaravilli F, Fowler CJ, Anand P (2004) Parallel changes in bladder suburothelial vanilloid receptor TRPV1 and pan-neuronal marker PGP9.5 immunoreactivity in patients with neurogenic detrusor overactivity after intravesical resiniferatoxin treatment. BJU Int 93:770-776.

Brierley SM, Jones III RC, Gebhart GF, Blackshaw LA (2004) Splanchnic and pelvic mechanosensory afferents signal different qualities of colonic stimuli in mice. Gastroenterology 127:166-178.

Burnstock G (1996) A unifying purinergic hypothesis for the initiation of pain. Lancet 347:1604-1605.

Caterina MJ, Schumacher MA, Tominaga M, Rosen TA, Levine JD, Julius D (1997) The capsaicin receptor: a heat-activated ion channel in the pain pathway. Nature 389:816-824.

Caterina MJ, Leffler A, Malmberg AB, Martin WJ, Trafton J, Petersen-Zeitz KR, Koltzenburg M, Basbaum AI, Julius D (2000) Impaired nociception and pain sensation in mice lacking the capsaicin receptor. Science 288:306-313.

Chen S, Rio C, Ji RR, Dikkes P, Coggeshall RE, Woolf CJ, Corfas G (2003) Disruption of ErbB receptor signaling in adult non-myelinating Schwann cells causes progressive sensory loss. Nat Neurosci 6:1186-1193.

Cockayne DA, Hamilton SG, Zhu QM, Dunn PM, Zhong Y, Novakovic S, Malmberg AB, Cain G, Berson A, Kassotakis L, Hedley L, Lachnit WG, Burnstock G, McMahon SB, Ford AP (2000) Urinary bladder hyporeflexia and reduced pain-related behaviour in P2X3-deficient mice. Nature 407:1011-1015.

Dang K, Bielefeldt K, Gebhart GF (2004) Distinct P2X receptors on lumbo- sacral and thoracolumbar dorsal root ganglion neurons innervating the rat uninary bladder. Soc Neurosci Abstr 30:281.

Dickenson AH, Dray A (1991) Selective antagonism of capsaicin by capsazepine: evidence for a spinal receptor site in capsaicin-induced antinociception. Br J Pharmacol 104:1045-1049.

Dirajlal S, Pauers LE, Stucky CL (2003) Differential response properties of IB(4)-positive and -negative unmyelinated sensory neurons to protons and capsaicin. J Neurophysiol 89:513-524.

Dunn PM, Zhong Y, Burnstock G (2001) P2X receptors in peripheral neurons. Prog Neurobiol 65:107-134.

Gold MS, Traub RJ (2004) Cutaneous and colonic rat DRG neurons differ with respect to both baseline and PGE2-induced changes in passive and active electrophysiological properties. J Neurophysiol 91:2524-2531.

Hesselager M, Timmermann DB, Ahring PK (2004) pH dependency and desensitization kinetics of heterologously expressed combinations of acid-sensing ion channel subunits. J Biol Chem 279:11006-11015.

Jarvis MF, Burgard EC, McGaraughty S, Honore P, Lynch K, Brennan TJ, Subieta A, Van Biesen T, Cartmell J, Bianchi B, Niforatos W, Kage K, Yu H, Mikusa J, Wismer CT, Zhu CZ, Chu K, Lee CH, Stewart AO, Polakowski J, et al. (2002) A-317491, a novel potent and selective nonnucleotide antagonist of $\mathrm{P} 2 \mathrm{X} 3$ and $\mathrm{P} 2 \mathrm{X} 2 / 3$ receptors, reduces chronic inflammatory and neuropathic pain in the rat. Proc Natl Acad Sci USA 99:17179-17184.

Kobayashi K, Fukuoka T, Yamanaka H, Dai Y, Obata K, Tokunaga A, Noguchi K (2005) Differential expression patterns of mRNAs for P2X receptor subunits in neurochemically characterized dorsal root ganglion neurons in the rat. J Comp Neurol 481:377-390.

Kontani H, Hayashi K (1997) Urinary bladder response to hypogastric nerve stimulation after bilateral resection of the pelvic nerve or spinal cord injury in rats. Int J Urol 4:394-400.

McCleskey EW, Gold MS (1999) Ion channels of nociception. Annu Rev Physiol 61:835-856.

McMahon SB (1997) Are there fundamental differences in the peripheral mechanisms of visceral and somatic pain? Behav Brain Sci 20:381-391.

Meen M, Coudore-Civiale MA, Eschalier A, Boucher M (2001) Involvement of hypogastric and pelvic nerves for conveying cystitis induced nociception in conscious rats. J Urol 166:318-322.

Mitsui T, Kakizaki H, Matsuura S, Ameda K, Yoshioka M, Koyanagi T (2001) Afferent fibers of the hypogastric nerves are involved in the facilitating effects of chemical bladder irritation in rats. J Neurophysiol 86:2276-2284.

Moss NG, Harrington WW, Tucker MS (1997) Pressure, volume, and chemosensitivity in afferent innervation of urinary bladder in rats. Am J Physiol 272:R695-R703.

Nadelhaft I, Vera PL (1991) Conduction velocity distribution of afferent fibers in the female rat hypogastric nerve. Brain Res 539:228-232.

Robergs RA, Ghiasvand F, Parker D (2004) Biochemistry of exerciseinduced metabolic acidosis. Am J Physiol Regul Integr Comp Physiol 287:R502-R516.

Sengupta JN, Gebhart GF (1994) Mechanosensitive properties of pelvic nerve afferent fibers innervating the urinary bladder of the rat. J Neurophysiol 72:2420-2430.

Shea VK, Cai R, Crepps B, Mason JL, Perl ER (2000) Sensory fibers of the pelvic nerve innervating the rat's urinary bladder. J Neurophysiol 84:1924-1933.

Steen KH, Reeh PW, Anton F, Handwerker HO (1992) Protons selectively induce lasting excitation and sensitization to mechanical stimulation of nociceptors in rat skin, in vitro. J Neurosci 12:86-95.

Stoop R, Surprenant A, North RA (1997) Different sensitivities to $\mathrm{pH}$ of ATP-induced currents at four cloned P2X receptors. J Neurophysiol 78:1837-1840.

Su HC, Wharton J, Polak JM, Mulderry PK, Ghatei MA, Gibson SJ, Terenghi G, Morrison JF, Ballesta J, Bloom SR (1986) Calcitonin gene-related peptide immunoreactivity in afferent neurons supplying the urinary tract: combined retrograde tracing and immunohistochemistry. Neuroscience 18:727-747.

Sun Y, Keay S, De Deyne PG, Chai TC (2001) Augmented stretch activated adenosine triphosphate release from bladder uroepithelial cells in patients with interstitial cystitis. J Urol 166:1951-1956. 
Tominaga M, Caterina MJ, Malmberg AB, Rosen TA, Gilbert H, Skinner K, Raumann BE, Basbaum AI, Julius D (1998) The cloned capsaicin receptor integrates multiple pain-producing stimuli. Neuron 21:531-543.

Virginio C, Robertson G, Surprenant A, North RA (1998) Trinitrophenylsubstituted nucleotides are potent antagonists selective for P2X1, P2X3, and heteromeric P2X2/3 receptors. Mol Pharmacol 53:969-973.

Vlaskovska M, Kasakov L, Rong W, Bodin P, Bardini M, Cockayne DA, Ford AP, Burnstock G (2001) P2 $\mathrm{X}_{3}$ knock-out mice reveal a major sensory role for urothelially released ATP. J Neurosci 21:5670-5677.

Vulchanova L, Riedl MS, Shuster SJ, Buell G, Surprenant A, North RA, Elde R (1997) Immunohistochemical study of the P2X2 and P2X3 receptor sub- units in rat and monkey sensory neurons and their central terminals. Neuropharmacology 36:1229-1242.

Vulchanova L, Riedl MS, Shuster SJ, Stone LS, Hargreaves KM, Buell G, Surprenant A, North RA, Elde R (1998) P2X3 is expressed by DRG neurons that terminate in inner lamina II. Eur J Neurosci 10:3470-3478.

Yoshimura N, Seki S, Erickson KA, Erickson VL, Hancellor MB, de Groat WC (2003) Histological and electrical properties of rat dorsal root ganglion neurons innervating the lower urinary tract. J Neurosci 23:4355-4361.

Zhong Y, Banning AS, Cockayne DA, Ford AP, Burnstock G, McMahon SB (2003) Bladder and cutaneous sensory neurons of the rat express different functional P2X receptors. Neuroscience 120:667-675. 